\title{
Heart rates during performance of a mental task under noise conditions '
}

\author{
C. G. COSTELlo ANo MARIA HALL \\ UNIVERSITY OF CALGARY
}

Gibson \& Hall (1966) reported that performance of mental tasks under noise conditions resulted in signific antly greater heart rate acceleration than performance under no-noise conditions. Three experiments are reported here. One is an exact replication of the Gibson and Hall experiment with essentially the same results. In a second experiment, it was found that noise alone did not result in heart rate acceleration. A third experiment found that extreme scorers on a scale of anxiety did not show heart rate acceleration under the Gibson and Hall conditions.

Gibson \& Hall (1966) reported that when Ss performed mental tasks under noise conditions their heart rates accelerated significantly more than did the heart rates of Ss performing mental tasks under a no-noise condition. They interpreted their results in terms of Lacey's theory (e.g., Lacey, Kagan, Lacey, \& Moss, 1962) according to which pressor-accelerative responses serve to filter out irrelevant stimuli that have distraction value for the performance of mental tasks.

In the first of the series of three studies reported here, it was found that $90 \mathrm{~dB}$ white noise alone did not produce a significant increase in the heart rates of Ss. Since the procedure in this study was the same as that of Gibson \& Hall (1966) apart from the fact that Ss were not required to perform mental tasks, no further details will be given. The second study was designed to test an alternative explanation of the findings reported by Gibson and Hall. This explanation would account for the increase in heart rate in terms of a stress reaction on the part of Ss. If this explanation is correct, then it would be expected that Ss predisposed to develop anxiety would show greater increases in heart rate in the Gibson and Hall situation than Ss with little predisposition to develop anxiety. Method

The Costello-Comrey Anxiety Scale(Costello \& Comrey, 1967) was administered to 500 freshman students during registration week. Twenty Ss with the highest scores and 20 with the lowest scores were selected for participation in the experiment. In the "high anxious" group there were 12 males and 8 females. In the "low anxious" group there were 5 males and 15 females.

Heart rate was recorded and the $90 \mathrm{~dB}$ white noise was presented as in the Gibson \& Hall (1966) study.

All Ss were required to construct grammatically correct sentences of eight words in which each word had to begin with the same letter. Difficulty of the mental task was manipulated by asking half the Ss to use the letter $\mathbf{P}$ and half to use the letter E. Gibson and Hall found that the Ss in their experiment took a significantly longer time to construct sentences when the letter $E$ was used than when the letter $P$ was used.

Ss within the high and low anxious groups were randomly assigned to the noise, no noise, and level of task difficulty conditions. The $\mathrm{E}$ (MKH) did not know to which anxlety group the $S$ belonged until after the completion of the experiment.

Basal heart rates were taken during a $15 \mathrm{~min}$ period before the mental task was presented.

Resulis

As in the experiment by Gibson \& Hall (1966) and following Lacey's (1956) method, the difference between the mean of the 12 highest heart rates during the pre-performance rest period and the mean of the 12 highest during problem solving was determined for each S, A second method of scoring was also used in which the mean rate per min during both preperformance rest period and problem solving period and the difference between these means were determined for each $\mathrm{S}$.

Analysis of variance of the data obtained with both scoring methods resulted in insignificant $F$ ratios for all the main effects and their interactions.

\section{Discussion}

Because of the absence of significant findings in the main experiment of this series, it was decided to attempt to replicate exactly the study by Gibson \& Hall (1966). Because the study was an exact replication, it will not be described in detail. It was found that, as in the Gibson and Hall experiment, constructing a sentence under noise conditions resulted in a greater heart rate increase than under no-noise conditions $(F=37.836$, df $=1 / 16, p<.01)$. The interaction of noise conditions with task difficulty was not significant in the Gibson and Hall experiment, though there was a tendency for the noise condition to result in a greater heart rate increase for Ss doing the easy task than for those doing the difficult task. This interaction was significant in the present experiment ( $F=20.283, \mathrm{df}=1 / 16, \mathrm{p}<.01$ ), the differences being in the same direction as in the Gibson and Hall experiment.

It now remains to be explained why Ss with scores at the extremes of an anxiety measure do not respond 
to this particular experimental manipulation in the manner of an unselected group of Ss.

\section{References}

Costello, C. G., \& Comrey, A. L. Scales of anxiety and depression. J. Psychol., 1967 (in press).

Gibson, D., \& Hall, M. Cardiovascular change and mental task gradient. Psychon. Sci., 1966, 6, 245-246.

Lacey, J. I. The evaluation of autonomic responses toward a gen- eral solution. Ann. N. Y. Acad. Sci., 1956, 67, 123-164.

Lacey, J. I., Kagan, J., Lacey, B. C., \& Moss, H. A. The visceral level: Situational determinants and behavioral correlates of autonomic response patterns. In P. Knapp (Ed.), Expressions of the emotions in man. New York: International Universities Press, 1962.

\section{Note}

1. This work was supported by Canadian National Health Grant 608-7-96. 